\title{
Índice de divulgação socioambiental de empresas brasileiras: uma análise léxica e de conteúdo
}

Os papéis de vários atores podem influenciar moderado, fraco ou fortemente sobre as divulgações sociais e ambientais corporativas das companhias, dada a estrutura econômica do país, bem como o desenvolvimento do seu mercado financeiro. Por exemplo, os acionistas podem influenciar as divulgações sociais e ambientais corporativas por terem relação direta com a empresa e os credores influenciam as divulgações corporativas relacionadas ao desempenho ambiental das empresas, dentre outros. O objetivo deste artigo é verificar o nível quantitativo de divulgação socioambiental das empresas listadas no mercado de capitais brasileiro que estão engajadas em projetos de sustentabilidade estabelecidos pelas Nações Unidas, os Objetivos de Desenvolvimento Sustentável (ODS). Para o alcance desse objetivo dispõe-se de uma metodologia eminentemente quantitativa quanto a natureza dos dados e descritiva no que concerne ao objetivo proposto. Em termos procedimentais, utiliza-se dos artefatos da análise léxica e de conteúdo para filtrar os dados e determinar a criação do índice de Divulgação Social e Ambiental (IDSA). Os resultados apontam que, no ano de análise de 2018 poucas empresas listadas no mercado de capitais brasileiro aderiram aos propósitos dos ODS ou pelo menos não explicaram ou relataram informações convergentes com os propósitos da Agenda. No entanto, percebe-se que, as empresas que divulgaram o relatório de sustentabilidade alinhado com os ODS estão mais engajadas com as práticas de sustentabilidade do meio ambiente, não se preocupando, tão somente, com nível econômico empresarial.

Palavras-chave: Divulgação; Sustentabilidade; Desenvolvimento; IDSA.

\section{Index of socio-environmental disclosure of Brazilian companies: a lexical and content analysis}

\begin{abstract}
The roles of various actors can influence, moderately, weakly or strongly, the companies' corporate social and environmental disclosures, given the country's economic structure, as well as the development of its financial market. For example, shareholders can influence corporate social and environmental disclosures because they have a direct relationship with the company and creditors influence corporate disclosures related to companies' environmental performance, among others. The purpose of this article is to verify the quantitative level of socio-environmental disclosure of companies listed in the Brazilian capital market that are engaged in sustainability projects established by the United Nations, the Sustainable Development Goals (SDGs). To achieve this objective, an eminently quantitative methodology is available in terms of the nature of the data and descriptive with regard to the proposed objective. In procedural terms, it uses the artifacts of lexical and content analysis to filter the data and determine the creation of the Social and Environmental Disclosure Index (IDSA). The results show that, in the year of analysis of 2018, few companies listed in the Brazilian capital market adhered to the purposes of the SDGs or at least did not explain or report information converging with the purposes of the Agenda. However, it is clear that the companies that released the sustainability report in line with the SDGs are more engaged with environmental sustainability practices, and are not only concerned with the economic level of the company.
\end{abstract}

Keywords: Disclosure; Sustainability; Development; IDSA.

Topic: Contabilidade Geral

Reviewed anonymously in the process of blind peer

Caroline Shanassis de Azevedo Gomes Cavalcant

Universidade Federal de Pernambuco, Brasil

carolinescavalcanti@hotmail.com

José Jonas Alves Correia

Universidade Federal de Pernambuco, Brasil

http://lattes.cnpq.br/2582627606928274

http://orcid.org/0000-0003-4552-7263

profjonasalves@gmail.com

Antoniel dos Santos Gomes Filho (it)

Centro Universitário Vale do Salgado, Brasil

http://lattes.cnpq.br/9563145614494252

http://orcid.org/0000-0003-2230-4315

antoniel.historiacomparada@gmail.com

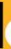

DOI: 10.6008/CBPC2674-6417.2020.001.0002
Received: 20/11/2019

Approved: 19/03/2020
Referencing this:

CAVALCANTI, C. S. A. G.; CORREIA, J. J. A.; GOMES FILHO, A. S.. Índice de divulgação socioambiental de empresas brasileiras: uma análise léxica e de conteúdo. Management Journal, v.2, n.1, p.13-26, 2020. DOI: http://doi.org/10.6008/CBPC2674-6417.2020.001.0002 


\section{INTRODUÇÃO}

A divulgação social e ambiental corporativa, como um diálogo entre as empresas e seus stakeholders interessados em atividades sociais e ambientais corporativas demonstra o cumprimento da responsabilidade social corporativa para com estes. Algumas dessas partes interessadas têm o poder de influenciar as decisões gerenciais de divulgar informações sociais e ambientais, e estudos anteriores demonstraram que as decisões de divulgação também são influenciadas por características corporativas (LIU et al., 2009; UNERMAN, 2007).

Os impactos socioambientais das empresas têm sido alvo de estudos de diversas ciências, inclusive a contábil, que estuda o modo como às organizações divulgam essa temática informacional em seus demonstrativos contábeis. Uma das teorias mais utilizadas para embasar a divulgação de informações ambientais nos relatórios financeiros é a Teoria da Legitimidade, cuja base argumenta que as entidades procuram divulgar informações relacionadas com a sustentabilidade a fim de passar para a sociedade uma impressão de boas práticas (BEUREN et al., 2013).

O Brasil e outros países em todo mundo estão adotando ações que visam alcançar as metas e indicadores contidos nos Objetivos de Desenvolvimento Sustentável (ODS), lançado pelas Nações Unidas. Aqui no Brasil, o primeiro passo na etapa de internalização da Agenda 2030 foi verificar a correspondência das metas dos ODS aos atributos estabelecidos pelo PPA 2016-2019, em mapeamento realizado no segundo semestre de 2016. A correspondência das metas e indicadores dos ODS com os atributos do PPA visa a identificar a congruência entre os objetivos declarados pela Agenda 2030 com o instrumento de planejamento do Governo Federal, vinculando a visão de médio prazo da atuação governamental com a expectativa de implantação dos compromissos constantes nos ODS.

Neste contexto sobre divulgação de informação social e sobre objetivos de manutenção de um mundo econômico, mas também sustentável, surge a seguinte questão problema: como as companhias que adotam as diretrizes dos Objetivos de Desenvolvimento Sustentável (ODS) têm divulgados suas informações sociais e ambientais em seus relatórios?. Nesta ótica, a pesquisa tem por objetivo verificar o nível quantitativo de divulgação socioambiental das empresas listadas no mercado de capitais brasileiro que estão engajadas em projetos de sustentabilidade estabelecidos pelas Nações Unidas.

De modo geral, a contribuição da pesquisa está no constructo de um Índice de Divulgação Social e Ambiental (IDSA). Tal índice foi criado baseado em pesquisas anteriores, o que acaba contribuindo externamente na validade do índice proposto nesta pesquisa. Com relação as métricas, utilizou-se da análise léxica e de conteúdo para obter dos dados mensurados no indicador. Ressalta-se que, o cálculo do IDSA para as companhias que apontaram divulgação do relatório de sustentabilidade alinhados aos ODS foi feito com auxílio de software que deram suporte na construção.

O restante deste artigo está organizado da seguinte forma. A seção 2 aponta a literatura relacionada à divulgação social e ambiental corporativa. A seção 3 explica os principais métodos utilizados na pesquisa, cujos resultados são descritos na seção 4. A quinta e última seção apresenta as considerações finais do estudo. 


\section{REVISÃO TEÓRICA}

Na literatura internacional, pesquisas a respeito da divulgação social e ambiental em empresas com grande volume de negócios acumularam uma série de estudos que examinaram os determinantes da divulgação (ROBERTS, 1992; HACKSTON et al., 1996; BRANCO et al., 2008; GARCÍA-SÁNCHEZ et al., 2013). No âmbito nacional também é crescente pesquisas sobre o nível de divulgação de informações ambientais em empresas atuantes no mercado de capitais brasileiro. Tais investigações têm sido feitas na sua maioria observando a quantidade de informações divulgadas sejam nos relatórios financeiros ou não financeiros das empresas listadas na bolsa de valores do país (CALIXTO, 2007; CUNHA et al., 2008; OLIVEIRA et al., 2012).

Com relação às características corporativas da divulgação discriminativamente observadas na literatura, estas incluem o tamanho, a lucratividade, a categoria econômica (indústria), o país de origem e a idade da empresa. Ainda que alguns determinantes tenham sido frequentemente identificados, os achados das investigações são distintos. No tocante ao tamanho da empresa, vários estudos identificam que as grandes empresas fizeram mais divulgação social e ambiental do que as pequenas empresas (CORMIER et al., 2001), já os achados de Roberts (1992) não encontraram relação entre o tamanho da empresa e o nível de divulgação social e ambiental corporativa.

Nesta mesma linha se raciocínio, estudos empíricos evidenciaram que a classificação da atividade econômica da empresa pode ter potencialidade em afetar a divulgação social e ambiental corporativa (BRANCO et al., 2008). No entanto, Gray et al. (1995) enfatizaram não haver clareza ou consistência para determinar com precisão os efeitos direcionados da associação da indústria sobre o nível de divulgação corporativa. Os achados empíricos sobre a relação de lucro e divulgação também são divergentes, alguns estudos não encontraram relação entre a lucratividade e a divulgação social e ambiental corporativa (HACKSTON et al., 1996), outros descobriram haver uma relação negativa (NEU et al., 1998), existindo ainda achados revelando ter uma relação positiva (CORMIER et al., 1999).

O poder dos stakeholders abarcam influências desempenhadas por vários grupos de stakeholders sobre as empresas, esses grupos são tipicamente formados por acionistas, credores, governos e de interesses especiais (GARCÍA-SÁNCHEZ et al., 2013). Trabalhos anteriores indicaram que, a divulgação social e ambiental corporativa está associada a vários grupos de partes interessadas: acionistas, influência governamental e grupos de interesse especial.

Percebe-se que a maior parte dos trabalhos investigados na literatura sobre divulgação social e ambiental é realizado em países desenvolvidos, existindo dessa forma, certa escassez de estudos focados em examinar os países emergentes com mercado de capitais menores. Mesmo já havendo trabalhos nacionais que examinaram o nível de divulgação das empresas brasileiras, esta pesquisa vem buscar preencher algumas lacunas visando aprofundar a investigação sobre as características corporativas e o poder dos stakeholders e sua associação com as empresas brasileiras.

Ao contrário dos estudos anteriores, tanto em contexto internacional como brasileiro, esta pesquisa mede a divulgação social e ambiental corporativa das perspectivas das stakeholders ao invés das perspectivas 
dos pesquisadores. Para tal, cria-se um índice de divulgação social e ambiental orientado aos stakeholders, que integra a quantidade de divulgação. Assim, examina o poder dos stakeholders como determinantes da divulgação social e ambiental, controlando as características corporativas que os estudos anteriores determinaram para influenciar tal divulgação. Esta investigação é realizada com empresas brasileiras listadas na bolsa de valores local, Bolsa, Brasil e Balcão, denominada B3.

\section{Teorias Adjacentes}

A Teoria da Legitimidade se atenta para explicar por que uma empresa faz divulgação social e ambiental e argumenta que uma empresa é legitimada quando seu sistema de valores corresponde ao sistema social de que faz parte e que a legitimidade é ameaçada quando o sistema de valores da empresa não corresponde ao do sistema social (LINDBLOM, 1994).

Segundo Woodward et al. (2001), a legitimidade, portanto, torna-se um recurso que uma empresa pode instituir, influenciar ou manipular através de várias estratégias relacionadas à divulgação. Desta forma, uma empresa pode ser motivada a divulgar informações sociais e ambientais para legitimar seu status dentro da sociedade (DEEGAN, 2002).

A estratégia relacionada à divulgação pode ser proativa para uma empresa obter ou manter o apoio do público em geral e grupos de interesse particulares ou reativos para reparar suas ameaças de legitimidade (CHO, 2009). Embora a Teoria da Legitimidade se centre nas expectativas da sociedade em geral, a Teoria dos Stakeholders se concentra nas expectativas de grupos de interesse particulares. Na conjuntura de uma empresa, a sociedade pode ser agrupada como acionistas, credores, funcionários, clientes e fornecedores, que podem estar interessados nas atividades sociais e ambientais da empresa.

Os stakeholders diferem na natureza e no nível de influência que exercem nas atividades de uma empresa. A natureza e o nível de influência se manifestam como poderes destes "agentes" e têm a capacidade de influenciar decisões estratégicas gerenciais sob a forma de controle sobre os recursos necessários para que a empresa continue a existir (ULLMANN, 1985). A divulgação social e ambiental corporativa deverá ser uma estratégia de gerenciamento eficaz para desenvolver e manter relacionamentos satisfatórios com potenciais interessados. A Teoria dos Stakeholders tenta explicar como uma empresa identifica os poderosos grupos que podem afetar ou ser afetados pelas práticas de divulgação social e ambiental da empresa e como a empresa responde às suas expectativas.

Neste diapasão, enfatiza que a Teoria da Legitimidade, que é vista como um aspecto dinâmico social e a Teoria dos Stakeholders, vista como o poder das partes nesta dinâmica, quando associadas fornecem duas perspectivas que oferecem pontos de vista diferentes e úteis. Assim, é pertinente abordá-las conjuntamente para fornecer explicações mais perspicazes para práticas de divulgação social e ambiental corporativa. O trabalho de Liu et al. (2009) discute a aplicação das teorias para analisar a divulgação social e ambiental na China.

Diante dessa discussão, partindo do pressuposto já respaldado pela literatura, esta pesquisa considerará a influência de quatro grupos de stakeholders, a saber: governo, acionista, credor e auditoria na 
divulgação social e ambiental corporativa. Os achados de Neu et al. (1998) apoiaram a visão de que grupos de stakeholders particulares podem ser mais eficazes na exigente divulgação social e ambiental corporativa, como acionistas e reguladores governamentais. Com base no estudo de Patten (1991) podem-se estabelecer relacionamentos entre as características corporativas de uma empresa, a saber: o tamanho da empresa, a lucratividade, a classificação da categoria econômica e a listagem no mercado de capitais externo e sua influência na divulgação social e ambiental corporativa.

Estudos anteriores sugerem que, as empresas com características empresariais preponderantes são mais propensas a serem examinadas pela sociedade, o que aumenta a necessidade de combinar seus valores com o da sociedade (PATTEN, 1991). Conforme Deegan (2002), as empresas com características corporativas proeminentes são mais propensas a fazer desconexões sociais e ambientais. No tocante às influências das características corporativas na divulgação social e ambiental em empresas brasileiras são pouco examinadas, desta forma, este estudo, testa sua validade empírica, além da influência do poder dos stakeholders.

\section{Poder dos Stakeholders}

O estudo de Roberts (1992) forneceu evidências empíricas para apoiar a perspectiva dos stakeholders de Freeman (1984), que reconhece a capacidade do governo de influenciar a estratégia e o desempenho das empresas por meios de regulamentos. Os achados de Liu et al. (2009) encontraram que, o governo chinês teve uma influência positiva e significativa sobre a divulgação ambiental de empresas chinesas listadas.

Estudos anteriores examinaram a possibilidade de os acionistas influenciarem a divulgação social e ambiental corporativa (CHOI, 1999). Keim (1978) assegura que, à medida que a distribuição de propriedade de uma empresa se torna menos concentrada, as demandas colocadas na empresa pelos acionistas tornamse mais amplas. A propriedade menos concentrada encoraja a administração a divulgar informações mais relevantes para atender às diversas demandas dos acionistas. Disseminação de propriedade corporativa aumenta a pressão para que a administração divulgue informações de responsabilidade social (ULLMANN, 1985).

Credores como fornecedores de capital são potenciais stakeholders que podem influenciar as atividades bem como os desvios das empresas. Roberts (1992) argumentou que quanto maior o grau em que uma empresa se baseia no financiamento da dívida, maior será o grau em que a gerência corporativa deverá responder às expectativas dos credores quanto ao papel da empresa nas atividades socialmente responsáveis.

Evidências empíricas sobre o relacionamento entre credor e divulgação são, no entanto, divergentes. Cormier et al. (2003) encontraram uma associação negativa entre subsídio financeira e divulgação, argumentando que apenas as empresas que são financeiramente sólidas (baixo grau de endividamento) podem negociar os benefícios da divulgação social e ambiental contra os custos de propriedade de revelálos.

As conclusões também apontam que, as empresas com baixo crescimento são mais propensas a se envolver em divulgação social e ambiental corporativa para garantir uma avaliação adequada do risco 
financeiro por parte dos participantes no mercado. À vista disso, com bases nos contrapontos dos achados anteriores, este estudo examina os efeitos dos credores sobre a divulgação social e ambiental corporativa no contexto brasileiro, para identificar o efeito direcional do poder credor sobre a divulgação social e ambiental corporativa.

Os auditores são profissionalmente influenciais em orientar seus clientes no início e na promoção de novas práticas contábeis, como no caso da contabilidade de responsabilidade social. A sociedade tende a perceber que empresas de auditoria maiores como as do grupo Big Four são mais justas e mais imparciais em suas opiniões de auditoria, pois são menos propensas a serem afetadas por suas empresas de clientes e a exercer a independência do auditor (CHOI, 1999; ANGELO, 1981). Corroborando com este argumento, Craswell et al. (1992) encontraram uma associação positiva entre a auditoria e a divulgação voluntária na indústria australiana de petróleo e gás.

Analisando empresas da Malásia, Ahmad et al. (2003) descobriram que as empresas auditadas pelos auditores do Big Four divulgaram mais informações ambientais em seus relatórios anuais. No estudo sobre divulgação de informações ambientais por empresas de alto impacto ambiental no Brasil, também foram encontradas evidências que atestam a relação significativa entre a auditoria independente pelas empresas da Big Four e a divulgação ambiental (MURCIA et al., 2008).

\section{Características Corporativas}

As empresas maiores são mais propensas e expostas ao público e, consequentemente, tendem a divulgar mais informações para obter suporte público para a sua existência contínua. Essas empresas têm mais acionistas que podem estar interessados em atividades sociais corporativas e são mais predispostos a usar a divulgação para comunicar resultados de empreendimentos sociais corporativos. O tamanho da empresa foi considerado um forte indicador que influencia as divulgações sociais e ambientais corporativas (CORMIER et al., 2001; ROVER et al., 2012).

Conforme Ullmann (1985), o desempenho econômico pode influenciar a capacidade financeira corporativa das empresas para realizar programas dispendiosos relacionados às demandas sociais. As empresas altamente lucrativas são aparentemente mais credíveis para o público, o que levanta expectativas sociáveis de responsabilidade. Estudos anteriores apoiam uma associação positiva entre o desempenho financeiro corporativo e a divulgação social e ambiental corporativa (CORMIER et al., 2003).

A maior visibilidade de um setor econômico pode impulsionar a divulgação, pois as empresas procuram evitar a pressão indevida e o crítico de ativistas sociais (PATTEN, 1991). Diferentes indústrias têm características diferentes que são moldadas pela intensidade da concorrência, visibilidade do consumidor e risco regulatório (ROBERTS, 1992). Essas características diferentes podem influenciar a divulgação social e ambiental corporativa e, portanto, a divulgação é específica da classe operacional. Dierkes et al. (1977) descobriram que, as empresas do setor de extração são mais propensas a divulgar informações sobre seus impactos ambientais do que as empresas em outros segmentos. Roberts (1992) demonstrou que, as empresas de alto nível de lucro, com alta visibilidade do consumidor, alto risco regulamentar ou competição 
intensa concentrada, são mais propícias a fazer maiores níveis de divulgação de responsabilidade social. Estudos indicam que os setores econômicos de alta proficiência provavelmente tornarão mais divulgação social e ambiental (HACKSTON et al., 1996).

\section{METODOLOGIA}

\section{Tipologia da Pesquisa}

Quanto ao objetivo estabelecido, esta pesquisa é classificada como exploratório-descritiva. O caráter exploratório se dar por examinar aspectos ligados a divulgação social e ambiental e outras características das empresas da B3 de uma forma pouca explorada em pesquisas nacionais, já pelo âmbito descritivo, busca-se descrever os principais achados pertinentes ao objeto de investigação. No que concerne à natureza dos dados e problema de pesquisa, o estudo é quantitativo. Dessa forma, apresenta resultados quantitativos relacionadas a quantidade de informações divulgadas pelas empresas listadas, com intuito de formar um índice de divulgação socioambiental.

\section{Amostra da Pesquisa}

A amostra do estudo consistiu nas empresas de capital aberto listadas na B3 que por meio do formulário de referência de 2019 (ano base 2018) apresentaram via relatório 'Relate ou Explique' informações em relação políticas socioambientais. O objetivo do Relate ou Explique é fomentar o entendimento dos Objetivos de Desenvolvimento Sustentável (ODS) e sua incorporação progressiva à estratégia empresarial das companhias listadas. A iniciativa é voluntária e aberta a todas as empresas listadas (B3, 2019). Depois de realizada uma análise minuciosa do relatório, algumas empresas foram retiradas da amostra por não apresentarem tais relatórios, restringindo-se a uma amostra final de 62 empresas no ano de 2018, que estão descritas na Tabela 1 conforme setor de atuação no mercado brasileiro.

Tabela 1: Distribuição das empresas da amostra

\begin{tabular}{|l|l|}
\hline Setor de atuação & Quantidade de empresas \\
\hline Bens industriais & 08 \\
\hline Consumo cíclico & 08 \\
\hline Consumo não cíclico & 06 \\
\hline Financeiro & 12 \\
\hline Materiais básico & 07 \\
\hline Saúde & 02 \\
\hline Petróleo, Gás e Biocombustíveis & 02 \\
\hline Telecomunicações & 02 \\
\hline Utilidade pública & 15 \\
\hline Total & $\mathbf{6 2}$ \\
\hline
\end{tabular}

\section{Procedimentos de Coleta de Dados}

Para coletar os dados utilizaram fontes secundárias, compostas pelos relatórios de sustentabilidade ou integrado. Cabe salientar que a divulgação dessas informações se dar de forma voluntária. Os relatórios analisados foram obtidos pelo link direto exposto no documento 'Relate ou Explique' para os ODS, no tempo em que o link não direcionava para tais demonstrativos, buscou-se direto nos sites das empresas. A análise 
dos relatórios já mencionados deu-se pelo fato destes evidenciarem informações socioambientais das organizações (NOSSA, 2002; MUSSOI et al., 2010), justificando-se assim, como exequível para mensurar o índice proposto nesta pesquisa.

\section{Divulgação Social e Ambiental e Procedimentos de Análise dos Dados}

$\mathrm{Na}$ abordagem quantitativa da pesquisa o intuito foi criar por meio da investigação um Índice de Divulgação Social e Ambiental (IDSA). Para tal, adotou-se metodologias já utilizadas por Marquezan et al. (2015) e por Viana Júnior et al. (2016), que usaram da na análise léxica e de conteúdo, dando assim, validade externa a esta pesquisa. Estudos internacionais que trataram do tema da responsabilidade socioambiental e adotaram metodologia semelhante também são destacados (KOTHARI et al., 2009; HANIFFA et al., 2005; KEARNEY et al., 2014).

A busca pelas palavras relacionadas à divulgação social e ambiental foi realizada por meio do software Atlas Ti versão 7. Desta forma, foi feito uma análise temática de conteúdo, procedimento que permite construir categorias analíticas ao examinar as informações extraídas das falas ou textos (MINAYO, 2007). Nesse sentido, Bauer et al. (2002) ressaltam que, na análise de conteúdo é exequível elaborar inferências sobre o conteúdo analisado por meio de indicadores, quer seja quantitativo ou não. Destarte, cada categoria formada se define como um código para a análise temática de conteúdo. Para detectar os códigos nos relatórios das empresas, utilizou-se o procedimento semântico, buscando os significados do que foi expresso pelo texto, formando assim dados quantitativos, calculados conforme a Equação 1.

$$
I D S A=\frac{\text { Número de palavras encontradas nos relatórios }}{\text { Quantidade de páginas de textos existentes nos relatorios }}
$$

O IDSA corresponde à razão entre número palavras/expressões chave contidas no relatório e a quantidade de páginas do relatório de sustentabilidade. As palavras-chave estão elucidadas no Quadro 1.

Quadro 1: Palavras-chave utilizadas para calcular o IDSA.

\begin{tabular}{|l|l|l|l|l|}
\hline Auditoria Ambiental & Gestão Ambiental & Sustentável & Emissão de Gás & Stakeholders \\
\hline Biodiversidade & Passivo Ambiental & Meio Ambiental & Energia Eficiente & Desempenho \\
\hline Conservação Ambiental & Poluição & ISO 14001 & Fauna & Governança \\
\hline Derramamento & Reciclagem & Energia Renovável & Flora & Auditoria \\
\hline $\begin{array}{l}\text { Desenvolvimento } \\
\text { Sustentável }\end{array}$ & Recursos Naturais & Custo Ambiental & Florestal & Sociedade \\
\hline Ecologia & Reutilização & Crédito de Carbono & Impacto Ambiental & Lucratividade \\
\hline Educação Ambiental & Reflorestamento & Dano Ambiental & Vazamento & Corporativo \\
\hline Efeito Estufa & Socioambiental & Ecológico & Resíduos & Big Four \\
\hline Energia Sustentável & Sustentabilidade & Efluentes & Ozônio & Rentabilidade \\
\hline
\end{tabular}

\section{RESULTADOS E DISCUSSÃO}

Esta seção analisa os resultados apontados na pesquisa. Cabe destacar que, será dado direcionamento aos índices de divulgação socioambiental obtido em cada setor como exposto na seção de metodologia. 


\section{Análise Geral do IDSA}

As companhias brasileiras muitas vezes utilizam além da divulgação de demonstrativos obrigatórios, da divulgação de informações voluntárias para mitigar lacunas na informação quanto à evolução de suas políticas econômicas, financeiras e sociais (SLEWINSKI et al., 2015). Dentre os meios de divulgações voluntárias aqui no Brasil, têm-se o relato integrado e o relatório de sustentabilidade.

Assim, a elaboração e divulgação do relatório de sustentabilidade são voluntárias, inclusive às companhias que sofrem influências regulatórias; entretanto, estas são estimuladas a comunicar práticas socioambientais, cabendo aos gestores decidir por elaborar ou não o relatório de sustentabilidade. A evidenciação voluntária de investimentos ambientais tornou- se rotina em muitas organizações, não só para cumprir regulamentações, mas, sobretudo, para demonstrar a preocupação ambiental e a responsabilidade social da empresa.

Neste contexto cabe ressaltar que, entre os dias 25 e 27 de setembro de 2015, em reunião dos chefes de Estado e dos representantes da Organização das Nações Unidas (ONU), foi assinada, em Nova York, a declaração que aprovou a existência dos Objetivos de Desenvolvimento Sustentável (ODS). Esses Objetivos fazem parte de uma agenda composta por metas globais para o desenvolvimento, intitulada como: 'Transformando Nosso Mundo: a Agenda 2030 para o Desenvolvimento Sustentável'. É uma Agenda de longo prazo, baseada em 17 objetivos e em 169 metas, que procuram traçar caminhos e interlocuções a respeito das prioridades, das capacidades e dos resultados alcançados em escala global.

Para tal, prevê ações nas áreas de erradicação da pobreza, segurança alimentar, agricultura, saúde, educação, igualdade de gênero, redução de desigualdades, energia, água e saneamento, padrões sustentáveis de produção e de consumo, mudança do clima, cidades sustentáveis, proteção e uso sustentável dos oceanos e dos ecossistemas terrestres, crescimento econômico inclusivo, industrialização, infraestrutura, entre outros.

Diante deste contexto e do já detalhado na metodologia da pesquisa, este estudo buscou criar um Índice de Divulgação Social e Ambiental das companhias brasileiras listadas. Deste modo, identificou-se empresas que atendiam de forma voluntária aos cumprimentos de divulgação de informações relativas aos Objetivos de Desenvolvimento Sustentável, que por meio de análise de conteúdo e de um conjunto de expressões convergentes com os planos e metas dos ODS, obteve-se os seguintes IDSA, como ilustrado na Tabela 2.

Tabela 2: Estatística descritiva do IDSA.

\begin{tabular}{|l|l|l|l|l|l|l|l|}
\hline & $\mathbf{N}$ & Mínimo & Máximo & Soma & Média & Erro Desvio & Variância \\
\hline IDSA & 62 & 174,29 & 1110,02 & 27214,22 & 438,9391 & 176,14676 & 31027,679 \\
\hline N válido (de lista) & 62 & & & & & & \\
\hline
\end{tabular}

A Figura 1 aponta o IDSA de forma genérica, isto é, o resultado abrangente para todas as companhias integrantes do estudo. Neste discurso, das 62 companhias que apresentaram ou explicaram a divulgação do relatório de sustentabilidade consonante aos Objetivos de Desenvolvimento Sustentável, tem-se que a companhia com menor índice foi PGB S.A $(174,29)$. O relatório de sustentabilidade da referida empresa 
apontou em 2018, um quantitativo de 89 páginas informativas sobre organismos corporativos da companhia. Cabe ressaltar que, a entidade se enquadra no segmento de bens industriais.

Segundo relatos da direção, a Portobello faz parte do Novo Mercado Bovespa desde abril de 2008, participando de um segmento de mercado com empresas que, voluntariamente, se comprometem a cumprir as mais exigentes normas de Governança Corporativa, que vão além do que é exigido pela legislação societária brasileira.

Em se tratando da empresa com o maior IDSA apurado em 2018, tem-se a Cia de Saneamento Básico do Estado de São Paulo (Sabesp) dentro do segmento de utilidade pública, cujo IDSA foi de 1.110,02, resultado que considerou o que a companhia divulgou de informações socioambientais dentro do seu relatório de sustentabilidade.

Uma observação interessante visualizada no relatório de sustentabilidade da Companhia é no tocante a preocupação com o desenvolvimento sustentável, que neste alinhamento, ressaltam que, com o entendimento de que a gestão ambiental requer envolvimento e compromisso das áreas operacionais para se elevar os níveis de eficiência, a Sabesp promoveu, ao longo dos últimos anos, um redirecionamento em sua estratégia de atuação, que por muitos anos teve foco absoluto na implantação das obras e serviços de saneamento. Desta forma, está cada vez mais empenhada na promoção de melhorias em seu parque operacional, visando ao atendimento da legislação ambiental e o desenvolvimento sustentável.

\section{Comportamento do IDSA por Setor de Atuação}

Outra forma de analisar o Índice de Divulgação Socioambiental foi observando o resultado setorial, como menciona Melo (2014), a maioria das empresas atua em setor de alto impacto ambiental no exercício de suas atividades tais como o setor de energia elétrica, petroquímicos, papel e celulose siderurgia e minerais metálicos. Outras atividades, tais como a prestação de serviços, embora o impacto ambiental não esteja diretamente associado à atividade principal, decorrem da sua própria atividade administrativa. Como visto na metodologia, nesta pesquisa as empresas que relataram informações socioambientais visando os ODS foram dos setores que vão de bens industriais à utilidade pública.

Tabela 3: Estatística descritiva: distribuição percentil do IDSA

\begin{tabular}{|l|l|l|l|}
\hline \multicolumn{2}{|l|}{} & Empresa & IDSA \\
\hline $\mathrm{N}$ & Válido & $\mathbf{6 2}$ & $\mathbf{6 2}$ \\
\hline Mínimo & & 174,29 \\
\hline Máximo & & 1110,02 \\
\hline Percentis & 10 & & $\mathbf{2 7 9 , 4 4 2 9}$ \\
\cline { 2 - 4 } & 20 & & $\mathbf{2 9 9 , 8 0 9 3}$ \\
\cline { 2 - 4 } & 30 & & 331,8064 \\
\cline { 2 - 4 } & 40 & & 357,1719 \\
\cline { 2 - 4 } & 50 & & 401,7507 \\
\hline & 60 & & 433,1060 \\
\hline & 70 & 475,5738 \\
\hline & 80 & 552,4151 \\
\hline & 90 & 692,8574 \\
\hline
\end{tabular}

De posse da base nos dados coletados das 62 companhias listadas com divulgação socioambiental ao ODS, organizou-se os resultados do IDSA de cada empresa e coloco em uma planilha no Excel, depois rodou 
por meio de estatística não paramétrica no software SPPS 25, com intuito de distribuir os valores dos IDSA individuais em percentis para mostrar uma distribuição mais uniforme entre as empresas.

Após a distribuição percentil, a distribuição dos IDSA se ajusta entre todas as 62 empresas. No primeiro percentil que apresenta os menores índices estão fica em torno de 279,44 para o menor, já para o maior IDSA que se encontra na outra extremidade, no décimo percentil esse valor é de 692,85. Após esse ajuste não paramétrico, a Tabela 4 aponta por setor, qual companhia obteve o maior IDSA em 2018.

Tabela 4: Maior IDSA por empresa no setor.

\begin{tabular}{|l|l|l|}
\hline Setor de atuação & Companhia & IDSA 2018 \\
\hline Bens industriais & JSL S. A. & 647,2951 \\
\hline Consumo cíclico & Lojas Renner S. A. & 451,0411 \\
\hline Consumo não cíclico & Minerva S. A. & 791,4444 \\
\hline Financeiro & BNDES Participações S. A. & 689,8625 \\
\hline Materiais básico & Suzano Holding S. A. & 567,2361 \\
\hline Saúde & Fleury S. A. & 337,8667 \\
\hline Petróleo, Gás e Biocombustíveis & Petrobrás Distribuidora S. A. & 453,2935 \\
\hline Telecomunicações & Algar Telecom S. A. & 300,2000 \\
\hline Utilidade pública & Cia Saneamento Básico do Est. São Paulo & $1.110,0189$ \\
\hline
\end{tabular}

Para analisar alguns aspectos de divulgação social e ambiental das companhias que apontaram maiores IDSA, como visto na Tabela 4, realizou-se uma análise de conteúdo, cujo relatos são apresentados na Tabela 5. Focou-se no desenvolvimento sustentável (desempenho ambiental), que de certo modo é o pilar base para os Objetivos de Desenvolvimento Sustentável estabelecidos na Agenda entre nações, cujos itens são relatados a seguir.

Tabela 5: Resultados da análise de conteúdo.

\begin{tabular}{|c|c|}
\hline Companhia & Relato da empresa \\
\hline JSL S. A. & $\begin{array}{l}\text { Sempre atenta à redução de impactos ambientais e visando contribuir com a conscientização sobre a } \\
\text { sustentabilidade, a JSL adota condutas que proporcionam a redução de consumo e resíduos, tais como o } \\
\text { uso racional do combustível e a realização do inventário de emissões. De acordo com as diretrizes do GHG } \\
\text { Protocol, a JSL realiza a cada ano seu Inventário de Emissões, ferramenta utilizada internacionalmente } \\
\text { para entender, quantificar e gerenciar emissões de gases de efeito estufa (GEE). }\end{array}$ \\
\hline Lojas Renner S. A. & $\begin{array}{l}\text { No novo foco, a gestão do consumo de água, começamos a implementar em dois fornecedores de jeans } \\
\text { um diagnóstico da gestão hídrica para, a partir do estabelecimento de indicadores de desempenho } \\
\text { ambiental, pegada hídrica e circularidade de águas, promovermos melhorias na gestão e redução do } \\
\text { consumo de água no processo produtivo. O desafio para os próximos anos é transformar as melhorias } \\
\text { capturadas em processos replicáveis para que a Produção Mais Limpa seja incorporada na rotina dos } \\
\text { fornecedores e a redução da geração de resíduos conquistadas se amplie de maneira orgânica. }\end{array}$ \\
\hline Minerva S. A. & $\begin{array}{l}\text { Por meio do Sistema de Gestão Ambiental (SGA), a Companhia realiza controles documentados, com o } \\
\text { apoio do SGI, o que permite a padronização dos processos nas plantas industriais do Brasil. A Companhia } \\
\text { atende aos requisitos legais aplicáveis às suas atividades, por meio de instrumentos de gerenciamento } \\
\text { adequado de resíduos sólidos, efluentes líquidos e emissões atmosféricas, em todas as unidades. }\end{array}$ \\
\hline $\begin{array}{l}\text { BNDES } \\
\text { Participações S. A. }\end{array}$ & $\begin{array}{l}\text { Em 2018, iniciamos um esforço interno de identificação das metas dos Objetivos de Desenvolvimento } \\
\text { Sustentável para as quais podemos contribuir e de nosso potencial de contribuição para cada uma delas. } \\
\text { Com base nesse resultado, espera-se estabelecer uma ponte metodológica entre nosso planejamento } \\
\text { estratégico, nossas Políticas Operacionais e nossa análise de efetividade. }\end{array}$ \\
\hline $\begin{array}{l}\text { Suzano Holding S. } \\
\text { A. }\end{array}$ & $\begin{array}{l}\text { Além disso, estamos comprometidos com os Objetivos do Desenvolvimento Sustentável (ODS), que são } 17 \\
\text { objetivos globais estabelecidos pela Assembleia Geral da ONU visando engajar empresas, governos e } \\
\text { instituições em uma agenda comum sustentável. Nosso objetivo é ter protagonismo no setor em que } \\
\text { atuamos e, por meio dele, ser um agente transformador da sociedade. Queremos mostrar que é possível } \\
\text { ser lucrativo, tendo um modelo inclusivo e respeitoso com as pessoas e o meio ambiente. Não vamos nos } \\
\text { furtar, por exemplo, de participar de debates em pautas urgentes para o país, como é o caso da educação, } \\
\text { que afeta o desenvolvimento do Brasil. }\end{array}$ \\
\hline Fleury S. A. & $\begin{array}{l}\text { A cada três anos, avaliamos os principais impactos e relações associados ao nosso negócio por meio do } \\
\text { Ciclo Estratégico de Sustentabilidade, um importante insumo para mapearmos tendências do setor, } \\
\text { demandas de stakeholders e desafios e oportunidades ligados ao amadurecimento da gestão quanto a } \\
\text { tópicos socioambientais e econômicos. O atual Ciclo Estratégico se estenderá até } 2020 \text {. }\end{array}$ \\
\hline
\end{tabular}




\begin{tabular}{|c|c|}
\hline $\begin{array}{l}\text { Petrobrás } \\
\text { Distribuidora S. A. }\end{array}$ & $\begin{array}{l}\text { Adotamos as diretrizes para relato de sustentabilidade da Global Reporting Initiative (GRI Standards). } \\
\text { Apresentamos também a correlação das atividades da empresa com os Princípios do Pacto Global e com } \\
\text { os Objetivos de Desenvolvimento Sustentável (ODS) das Nações Unidas. }\end{array}$ \\
\hline $\begin{array}{l}\text { Algar Telecom S. } \\
\text { A. }\end{array}$ & $\begin{array}{l}\text { Redução dos impactos ambientais, de acordo com as prioridades estabelecidas pela Matriz de } \\
\text { Relevância, e diagnóstico de emissão de gases efeito estufa feito pela Companhia: Conforme nossa } \\
\text { Matriz de Relevância, a gestão da emissão de gases de efeito estufa e de resíduos é a nossa prioridade } \\
\text { com relação à mitigação de impactos ambientais. Nesse sentido, em 2018, alcançamos uma importante } \\
\text { conquista, com a implantação de uma usina de geração de energia fotovoltaica, contribuindo para a } \\
\text { redução de gases de efeito estufa. O diagnóstico de nossa emissão é consolidado em relatórios baseados } \\
\text { na metodologia do GHG Protocol e auditados anualmente. }\end{array}$ \\
\hline $\begin{array}{l}\text { Cia Saneamento } \\
\text { Básico do Est. São } \\
\text { Paulo }\end{array}$ & $\begin{array}{l}\text { A Companhia apoia e incentiva os } 17 \text { Objetivos de Desenvolvimento Sustentável (ODS), mais uma } \\
\text { iniciativa da ONU, que visa estimular ações para os próximos } 15 \text { anos em áreas de importância crucial para } \\
\text { a humanidade, o planeta, os países e as empresas. Os ODS estão integrados no Programa de Voluntariado } \\
\text { Empresarial, que tem como objetivo realizar ações e incentivar mudanças de comportamento que } \\
\text { contribuam de forma mais ampla para o desenvolvimento social da população que está sob sua influência. }\end{array}$ \\
\hline
\end{tabular}

Diante do reportado na Tabela 5, percebe-se que, todas as empresas que apresentaram maiores indicadores de divulgação social e ambiental em seu segmento de atuação relatam informações pertinentes aos Objetivos de Desenvolvimento Sustentável. Como apontam Correia et al. (2017), muitas empresas cumprem seja compulsório ou voluntariamente a divulgação desse tipo de informações como forma de se legitimar para seus stakeholders.

\section{CONCLUSÕES}

A pesquisa teve por objetivo verificar o nível quantitativo de divulgação socioambiental das empresas listadas no mercado de capitais brasileiro que estão engajadas em projetos de sustentabilidade estabelecidos pelas Nações Unidas. O alcance do objetivo se deu pela criação de um índice que apontou por meio de uma análise léxica um indicativo de expressões que conversam com as informações divulgadas no âmbito socioambiental. Assim, foi apontado os indicadores das 62 empresas que reportaram informações congruentes com o estabelecido pela ONU na agenda que determinou os Objetivos de Desenvolvimento Sustentável.

De modo geral a pesquisa enfatiza que, as companhias brasileiras listadas no mercado de capitais deste país precisam se alinhar mais com os propósitos das ações de sustentabilidade do planeta. Fato é que apenas 62 empresas apontaram e divulgaram relatórios de sustentabilidade em compatibilidade no exercício estudado, 2018.

Um contraponto que talvez explique essa pouca adesão, quiçá seja pela mudança no direcionamento do resultado das informações a serem reportadas, que até 2016 no questionário 'Relate ou Explique' tinha uma finalidade de exposição de informações sociais, ambientais e de governança corporativa e somente a partir do ano base 2017, o questionário foi se adequando a capturar informações focadas nos ODS.

Em termos de limitações da pesquisa, cita-se a pouca amostra investigada. Se levado em consideração todo o conjunto das companhias listadas, a obtenção de apenas 62 empresas é pouco significativa, embora tenha sua representatividade. Outra limitação é tocante ao corte temporal, que se limitou ao exercício fiscal (ano referência) de 2018. Tal construção baseada em um único período acaba perdendo poder de comparabilidade entre outros tempos em que se divulgou as informações socioambientais. 
Assim, sugere-se que novas pesquisas mergulhem em horizontes maiores, neste caso, congregue em novos estudos todo o tempo de adesão das companhias ao ODS. Sugere-se também que novos estudos aprofundam a análise tanto quantitativa como qualitativamente, fazendo uso de novas métricas para ver a associação do IDSA com outras caraterísticas das entidades. Que possam também mergulhar no aspecto qualitativo, observando de forma minuciosa as informações reportadas nos relatórios das companhias.

\section{REFERÊNCIAS}

AHMAD, Z.; HASSAN, S.; MOHAMMAD, J.. Determinants of environmental reporting in Malaysia. International Journal of Business Studies, v.11, n.1, p.69, 2003.

ANGELO, L. E.. Auditor size and audit quality. Journal of Accounting and Economics, v.3, n.3, p.183-199, 1981.

BAUER, M. W.; GASKELL, G.. Pesquisa qualitativa com texto imagem e som: Um manual prático. Rio de Janeiro: Vozes, 2002.

BEUREN, I. M.; GUBIANI, C. A.; SOARES, M.. Estratégias de Legitimidade de Suchman evidenciadas nos relatórios da administração de empresas públicas do setor elétrico. Revista de Administração Pública, v.47, n.4, p.849-875, 2013.

BRANCO, M. C.; RODRIGUES, L. L.. Factors influencing social responsibility disclosure by Portuguese companies. Journal of Business Ethics, v.83, n.4, p.685-701, 2008.

CALIXTO, L.. Uma análise da evidenciação ambiental de companhias brasileiras de 1997 a 2005. Contabilidade, Gestão e Governança, v.10, n.1, p.9-37, 2007.

$\mathrm{CHO}, \mathrm{C}$. H.. Legitimation strategies used in response to environmental disaster: A French case study of Total SA's Erika and AZF incidents. European Accounting Review, v.18, n.1, p.33-62, 2009.

CHOI, J. S.. An investigation of the initial voluntary environmental disclosures made in Korean semi-annual financial reports. Pacific Accounting Review, v.11, n.1, p.73, 1999.

CORMIER, D.; GORDON, I. M.. An examination of social and environmental reporting strategies. Accounting, Auditing \& Accountability Journal, v.14, n.5, p.587-617, 2001.

CORMIER, D.; MAGNAN, M.. Corporate environmental disclosure strategies: determinants, costs and benefits. Journal of Accounting, Auditing \& Finance, v.14, n.4, p.429-451, 1999.

CORMIER, D.; MAGNAN, M.. Environmental reporting management: a continental European perspective. Journal of Accounting and Public Policy, v.22, n.1, p.43-62, 2003.

CORREIA, J. J. A.; SILVA, F. E. A. D.; RODRIGUES, R. N.. Evidenciação socioambiental de empresas siderúrgicas brasileiras entre 2011 e 2015: análise dos relatórios financeiros e de sustentabilidade. Revista Brasileira de Gestão Ambiental e Sustentabilidade, v.4, n.8, p.327-341, 2017.
CRASWELL, A. T.; TAYLOR, S. L.. Discretionary disclosure of reserves by oil and gas companies: An economic analysis. Journal of Business Finance \& Accounting, v.19, n.2, p.295-308, 1992.

CUNHA, J. V. A.; RIBEIRO, M.. Divulgação voluntária de informações de natureza social: um estudo nas empresas brasileiras. Revista de Administração, v.1, n.1, p.1-23.

DEEGAN, C.. Introduction: The legitimizing effect of social and environmental disclosures-a theoretical foundation. Accounting, Auditing \& Accountability Journal, v.15, n.3, p.282-311, 2002.

DIERKES, M.; PRESTON, L. E.. Corporate social accounting reporting for the physical environment: A critical review and implementation proposal. Accounting, Organizations and Society, v.2, n.1, p.3-22, 1977.

FREEMAN, R.. Strategic Management: a Stakeholder Approach. Marshfield: Pitman, 1984.

GARCÍA-SÁNCHEZ, I. M.; FRÍAS-ACEITUNO, J. V.; RODRÍGUEZDOMÍNGUEZ, L.. Determinants of corporate social disclosure in Spanish local governments. Journal of Cleaner Production, v.39, p.60-72, 2013.

GRAY, R.; KOUHY, R.; LAVERS, S.. Corporate social and environmental reporting: a review of the literature and a longitudinal study of UK disclosure. Accounting, Auditing \& Accountability Journal, v.8, n.2, p.47-77, 1995.

HACKSTON, D.; MILNE, M. J.. Some determinants of social and environmental disclosures in New Zealand companies. Accounting, Auditing \& Accountability Journal, v.9, n.1, p.77-108, 1996.

HANIFFA, R. M.; COOKE, T. E.. The impact of culture and governance on corporate social reporting. Journal of Accounting and Public Policy, v.24, n.5, p.391-430, 2005.

KEARNEY, C.; LIU, S.. Textual sentiment in finance: A survey of methods and models. International Review of Financial Analysis, v.33, p.171-185, 2014.

KEIM, G. D.. Managerial behavior and the social responsibility debate: Goals versus constraints. Academy of Management Journal, v.21, n.1, p.57-68, 1978.

KOTHARI, S. P.; XU, L.; SHORT, J.. The effect of disclosures by management, analysts, and business press on cost of capital, return volatility, and analyst forecasts: A study using content analysis. Accounting Review, v.84, n.5, p.1639-1670, 2009.

LINDBLOM, C. K.. The implications of organizational 
legitimacy for corporate social performance and disclosure. In: CRITICAL PERSPECTIVES ON ACCOUNTING CONFERENCE. Anais. New York, 1994.

LIU, X.; ANBUMOZHI, V.. Determinant factors of corporate environmental information disclosure: an empirical study of Chinese listed companies. Journal of Cleaner Production, v.17, n.6, p.593-600, 2009.

MARQUEZAN, L. H. F.; SEIBERT, R. M.; BARTZ, D.; BARBOSA, M. A. G.; ALVES, T. W.. Análise dos determinantes do disclosure verde em relatórios anuais de empresas listadas na BM\&FBovespa. Contabilidade, Gestão e Governança, v.18, n.1, p.127-150, 2015.

MINAYO, M. C. S.. O Desafio do Conhecimento: Pesquisa Qualitativa em Saúde. 10 ed. São Paulo: HUCITEC, 2007.

MURCIA, F. D. R.; ROVER, S.; LIMA, I.; FÁVERO, L. P.; LIMA, G.. 'Disclosure Verde'nas Demonstrações Contábeis: Características da Informação Ambiental e Possíveis Explicações para a Divulgação Voluntária. Contabilidade, Gestão e Governança, v.11, n.1-2, p.260-278, 2008.

MUSSOI, A.; VAN BELLEN, H. M.. Evidenciação ambiental: uma comparação do nível de evidenciação entre os relatórios de empresas brasileiras. Revista de Contabilidade e Organizações, v.4, n.9, p.55-78, 2010.

NEU, D.; WARSAME, H.; PEDWELL, K.. Managing public impressions: environmental disclosures in annual reports. Accounting, Organizations and Society, v.23, n.3, p.265-282, 1998.

NOSSA, V.. Disclosure ambiental: uma análise do conteúdo dos relatórios ambientais de empresas do setor de papel e celulose em nível internacional. Tese (Doutorado) Universidade de São Paulo, São Paulo, 2002.

OLIVEIRA, M. C.; ARAÚJO JÚNIOR, J. F.; OLIVEIRA, O. V.; PONTE, V. M. R.. Disclosure social de empresas brasileiras e britânicas à luz da teoria institucional. Advances in Scientific and Applied Accounting, v.5, n.1, p.2-26, 2012.

PATTEN, D. M.. Exposure, legitimacy, and social disclosure. Journal of Accounting and Public Policy, v.10, n.4, p.297-308, 1991.

ROBERTS, R. W.. Determinants of corporate social responsibility disclosure: An application of stakeholder theory. Accounting, Organizations and Society, v.17, n.6, p.595-612, 1992.

ROVER, S.; TOMAZZIA, E. C.; MURCIA, F. D. R.; BORBA, J. A.. Explicações para a divulgação voluntária ambiental no Brasil utilizando a análise de regressão em painel. Revista de Administração, v.47, n.2, p.217-230, 2012.

SLEWINSKI, E.; GONÇALVES, M. N.; SANCHES, S. L. R. Determinantes da divulgação do relatório de sustentabilidade ou do relato integrado das empresas listadas na BM\&FBovespa. In: CONGRESSO ANPCONT, 9. Anais. Curitiba, 2015.

ULLMANN, A. A.. Data in search of a theory: A critical examination of the relationships among social performance, social disclosure, and economic performance of US firms. Academy of Management Review, v.10, n.3, p.540557, 1985.

UNERMAN, J.. Stakeholder engagement and dialogue. In: UNERMAN, J.; BEBBINGTON, J.; O'DWYER, B.. Sustainability Accounting and Accountability. New York: Routledge, 2007. p.86-103.

VIANA JÚNIOR, D. B. C.; CRISÓSTOMO, V. L.. Nível de disclosure ambiental das empresas pertencentes aos setores potencialmente agressivos ao meio ambiente.

Contabilidade, Gestão e Governança, v.19, n.2, p.254-273, 2016.

WOODWARD, D.; EDWARDS, P.; BIRKIN, F.. Some evidence on executives' views of corporate social responsibility. The British Accounting Review, v.33, n.3, p.357-397, 2001.

A CBPC - Companhia Brasileira de Produção Científica (CNPJ: 11.221.422/0001-03) detém os direitos materiais desta publicação. Os direitos referem-se à publicação do trabalho em qualquer parte do mundo, incluindo os direitos às renovações, expansões e disseminações da contribuição, bem como outros direitos subsidiários. Todos os trabalhos publicados eletronicamente poderão posteriormente ser publicados em coletâneas impressas sob coordenação da Sapientiae Publishing, da Companhia Brasileira de Produção Científica e seus parceiros autorizados. Os (as) autores (as) preservam os direitos autorais, mas não têm permissão para a publicação da contribuição em outro meio, impresso ou digital, em português ou em tradução. 